\author{
DOI: 10.12731/wsd-2017-2-184-199 \\ УДК 614.2:616.314
}

\title{
ОЦЕНКА ОРГАНИЗАЦИИ ПРОФИЛАКТИКИ СТОМАТОЛОГИЧЕСКИХ ЗАБОЛЕВАНИЙ И СТОМАТОЛОГИЧЕСКОЙ ПОМОЩИ ВОЕННЫМ ПЕНСИОНЕРАМ
}

Фомина А.В., Тарараева Т.Ю.

Цель работы. На основе изучения самооченки состояния здоровья в иелом и стоматологического здоровья, оченки уровня оказания стоматологической помощи дать характеристику организаџии профилактики стоматологических заболеваний и стоматологической помощи военным пенсионерам.

Материалы и методы исследования. В основу исследования положены материаль социологического исследования самооценки состояния здоровья военных пенсионеров (300 анкет) и анализ карт выборки из медицинской документации по поводу обращения за стоматологической, в том числе ортопедчческой, помощью в учреждения здравоохранения, оказывающие медицинскую помощь данному контингенту (300 карт).

Результаты. Получена медико-сочиальная характеристика военных пенсионеров и их отношения к организации стоматологической помощи и профилактике стоматологических заболеваний. Среди причин обращения к стоматологу абсолютно превалирует необходимость протезирования в связи с частичной утратой зубов (76\%). Выполнение рекомендаций стоматолога имеет место только у 24,1\% респондентов и в их семьях. В большинстве случаев врачу стоматологу-ортопеду удается оказать необходимую стоматологическую помощь, однако в 7,2\% отмечается отсутствие результата, что связано с отсутствием данных пациентов на повторном приеме.

Заключение. Отмечается низкий уровень медииинской грамотности и информированности военных пенсионеров по вопросам профилактики и лечения стоматологических заболеваний. Данное исследование подтверждает необходимость разработки комплекса мероприятий по стоматологической реабилитации военных пенсионеров. 
Ключевые слова: стоматологическая заболеваемость; военные пенсионеры; стоматологическая помощьь.

\section{ASSESSMENT OF THE ORGANIZATION OF PREVENTION OF DENTAL DISEASES AND DENTAL CARE TO RETIREES}

\section{Fomina A.V., Tararaeva T.Ju.}

Background: To give a characteristic of the preventation of disease and dental care to military retirees organization based on the research of self-reported health status, dental health status and assessment of the dental care level.

Materials and methods: The research is based on sociological research of military retirees' self-reported health status materials (300 profiles) and analyses of the sample cards from medical documentation about recourses for dental care, orthopedic care, about recourses in medical institution which gives medical care for this contingent (300 cards).

Results: A medico-social characteristics of military retirees opinion about organization of dental care and prevention of dental diseases was made. Among the reasons for going dentist the absolutely biggest one is necessary to make a dental prosthesis because of missing teeth (76\%). Only 24,1\% of respondents are following dentist's recommendations. In most cases dentist can make a necessary dental care, but only in 7,2\% there is no result which is linked to patient's missing the second medical reception.

Conclusion: A low level of medical literacy knowledge about prevention of dental diseases and their treatment among military retirees was recorder. This research affirms the need of development the events about military retirees rehabilitation complex.

Keywords: dental morbidity; military retirees; dental care.

\section{Введение}

Увеличение численности пожилых людей требует более глубокого изучения демографических и социальных процессов, в том числе проблем пожилых людей, связанных с особенностями состояния здоровья [1, c. $4-13 ; 2$, с. $18 ; 3$, с. $307-315 ; 4$, с. 208].

По данным Федеральной службы государственной статистики, доля лиц старше трудоспособного возраста в Российской Федерации в насто- 
ящее время составляет около $25 \%$ всего населения и продолжает расти [5]. К 2050 году прогнозируется удвоение численности пожилых людей и утроение коэффициента демографической нагрузки пожилым населением [6, с. 243-252; 7, с. 7-26].

Возрастные изменения негативным образом отражаются на состоянии стоматологического здоровья граждан пожилого и старческого возраста и определяют рост потребности в стоматологической помощи, в том числе ортопедической [8; 9, с. 975-986]. Показатель распространенности проблем с полостью рта и зубами у пожилых людей, которые могут проявляться запущенным кариесом, широким распространением пародонтоза, потерей зубов, предраковыми состояниями полости рта, варьирует от $42 \%$ в странах с низким уровнем дохода до $29 \%$ в странах с высоким уровнем дохода [10].

Стоматологическая заболеваемость и потребность в стоматологической реабилитации военных пенсионеров имеют особенности. Это связано с более ранним выходом на пенсию офицеров по достижении предельного возраста пребывания на военной службе, с их пребыванием во время военной службы в разных регионах страны, недостаточным уровнем оказания стоматологической помощи по месту службы [11, с. 34-38; 12 , с. 54-58; 13, с. 24-25]. По данным Прохватилова Г.И. и соавт., распространенность кариеса во всех возрастных группах пенсионеров МО РФ была равна $100 \%$ при его интенсивности $14,15 \pm 0,22$. Отмечена закономерность преобладания пломбированных и удаленных зубов над элементом «кариес» $(67,3 \%, 21,2 \%$ и $11,5 \%$ соответственно в структуре индекса КПУ). Результаты исследования также показали высокую распространенность и интенсивность заболеваний пародонта у исследуемого контингента. Гигиена полости рта у 74,13\% пенсионеров оценена как плохая при среднем значении индекса $2,75 \pm 0,10$. Нуждаемость в протезировании пенсионеров МО РФ составила 40,29\% [12, с. 54-58].

Медико-социальная помощь населению пожилого возраста направлена на лечение имеющихся у них заболеваний и уход, поддержание их активного образа жизни и социальную защиту в случае болезни и неспособности удовлетворять основные жизненные потребности [14, c. 49-53; 15, с. 36-39]. Стоматологическая помощь пациентам пожилого и старческого возраста рассматривается в настоящее время с учетом всех экзогенных и эндогенных факторов, вызывающих патологические процессы в полости рта [16, с. 22-26]. При этом стоматологическая помощь отдельным категориям граждан, к которым можно отнести военных 
пенсионеров, оказывается, как территориальными учреждениями здравоохранения, так и военными лечебными учреждениями и медицинскими подразделениями стоматологического профиля, что отражается на формировании потоков пациентов $[17$, с. $52-53$; 18, с. 84-88; 19, с. 208-214; 20 , с. 78-80].

\section{Цель работы}

На основе изучения самооценки состояния здоровья в целом и стоматологического здоровья, оценки уровня оказания стоматологической помощи дать характеристику организации профилактики стоматологических заболеваний и стоматологической помощи военным пенсионерам.

\section{Материалы и методы исследования}

В основу исследования положены материалы социологического исследования самооценки состояния здоровья военных пенсионеров (300 анкет) и анализ карт выборки из медицинской документации по поводу обращения за стоматологической, в том числе ортопедической, помощью в учреждения здравоохранения, оказывающие медицинскую помощь данному контингенту (300 карт).

На основе анкеты и карты выкопировки создана база данных в программе SPSS корпорации IBM Corp. var. 2013. Данные представлены в виде количественных вариабельных (возраст, стаж военной службы, число удаленных, пломбированных и кариозных зубов, КПУ и др.), остальные - в виде категориальных вариабельных. Для анализа использованы: описательная статистика (средние арифметические и среднеквадратические отклонения (б), частоты и таблицы сопряженности), сравнение средних по критерию Т, вычисляли коэффициент ранговой корреляции Спирмена, построение графиков. При выявлении статистически достоверных различий по группам приводятся значения значимости отличий (p), а выбор критериев определяется видом вариабельных и характером их распределения. Уровень статистической надежности принят 95\% $(\mathrm{p}<0,05)$. Кроме того, для построения графиков использовалась программа Excel Microsoft.

\section{Результаты исследования и их обсуждение}

Исследуемая выборка состояла практически из мужчин, среди которых 95,6\% служили в сухопутных войсках, 4,4\% - морских. Все женщины $(1,3 \%)$ служили в сухопутных войсках. 




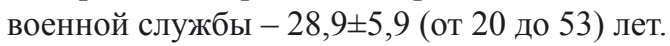

Основное место службы на территории России отметили 78,6\% респондентов, в том числе 57,3\% (173 чел.) - Западный военный округ, $13,0 \%$ (39 чел.) - Восточный военный округ, 5,7\% (17 чел.) - Центральный военный округ, 1,3\% (4 чел.) - Южный военный округ и 1,3\% (4 чел.) не указали военный округ, но служили в России. Кроме этого, 15\% (45 чел.) отметили как основное место службы страны СНГ (для лиц, служивших до 1991 г. республики СССР) и 1,0\% (3 чел.) - зарубежье дальнее. 16 чел. (5,3\%) не указали место службы.

Важным аспектом медико-социальной характеристики военных пенсионеров является семейное положение. Военные пенсионеры в $65,3 \%$ случаев проживают с супругой, в $27,7 \%$ - с супругой и детьми, $2,3 \%$ - с детьми без супруги, 2,7\% - одиноки, $0,3 \%$ - другие варианты и 1,7\% - не указали состав семьи. Таким образом, 93\% респондентов проживают совместно с супругой (ом) без детей или с детьми.

В ходе анализа полученных данных по самооценке здоровья только $0,7 \%$ (2 чел.) оценили свое здоровье как отличное, $10,7 \%$ - хорошее, $76,3 \%$ - удовлетворительное, 9,3\% - плохое, 0,7\% (2 чел.) - очень плохое и $0,3 \%$ ( 1 чел.) затруднились определить свое здоровье и 2 чел. не ответили на поставленный вопрос. В целом, 89,5\% оценили свое здоровье от отличного до удовлетворительного.

Влияние возраста и стажа службы на самооценку здоровья при 5 градациях самооценки здоровья представлено в табл. 1 .

Таблицуа 1.

Влияние возраста и стажа службы на самооценку здоровья при пяти градациях самооценки здоровья от «отлично» до «очень плохо»

\begin{tabular}{|c|c|c|c|c|}
\hline $\begin{array}{c}\text { Самооценка } \\
\text { здоровья }\end{array}$ & $\begin{array}{c}\text { Средний } \\
\text { возраст } \\
\text { (лет) }\end{array}$ & $\begin{array}{c}\text { Корреляционная } \\
\text { связь самооценки } \\
\text { здоровья и воз- } \\
\text { раста }\end{array}$ & $\begin{array}{c}\text { Средний } \\
\text { стаж (лет) }\end{array}$ & $\begin{array}{l}\text { Корреляционная } \\
\text { связь самооценки } \\
\text { здоровья и стажа }\end{array}$ \\
\hline Отлично & $51,5 \pm 20,5$ & \multirow{5}{*}{$\begin{array}{l}r=0,411 \\
(p=0,01)\end{array}$} & $22,0 \pm 2,8$ & \multirow{5}{*}{$\begin{array}{l}r=0,256 \\
(p=0,01)\end{array}$} \\
\hline Хорошо & $54,5 \pm 9,7$ & & $26,0 \pm 5,6$ & \\
\hline $\begin{array}{l}\text { Удовлетво- } \\
\text { рительно }\end{array}$ & $69,1 \pm 11,1$ & & $29,0 \pm 5,8$ & \\
\hline Плохо & $76,3 \pm 8,6$ & & $31,5 \pm 5,5$ & \\
\hline Очень плохо & $81,5 \pm 2,1$ & & $32,0 \pm 7,1$ & \\
\hline
\end{tabular}


Как видно из табл. 1, чем старше респонденты и, соответственно, чем больше стаж службы, тем хуже самооценка здоровья, о чем свидетельствует значение коэффициента корреляции средней (самооценка здоровья в зависимости от возраста) или слабой силы (самооценка здоровья в зависимости от стажа службы).

Принимая во внимание, что оценку отлично дали только 2 чел., причем наиболее молодых, проведена оптимальная категоризация возраста по самооценке здоровья (программа SPSS). Категоризация возраста по самооценке здоровья показала, что критическим возрастом является 62 года. При этом самооценка здоровья на основе логического и статистического анализа дала 3 категории самооценки здоровья (табл.2): отлично и хорошо $(11,6 \%)$, удовлетворительно $(78,2 \%)$, плохо и очень плохо $(10,2 \%)\left(\chi^{2}, \mathrm{p}<0,001\right)$.

Таблица 2.

Таблица сопряженности возрастных групп по самооценке здоровья

\begin{tabular}{|l|c|c|c|}
\hline \multirow{2}{*}{ Самооценка здоровья } & Вес группы & \multicolumn{2}{|c|}{ Уо самооцен- } \\
& ке здоровья & своего здоровья в возрастной группе \\
\cline { 3 - 4 } & $11,6 \%$ & $30,2 \%$ & 62 года и более \\
\hline Отлично, хорошо & $78,2 \%$ & $69,8 \%$ & $3,9 \%$ \\
\hline Удовлетворительно & $10,2 \%$ & $0 \%$ & $81,6 \%$ \\
\hline Плохо и очень плохо & $14,5 \%$ \\
\hline
\end{tabular}

Наиболее многочисленная группа по самооценке здоровья (72,8\%) представлена оценкой «удовлетворительно». Крайние варианты оценок составляют по 10-12\%. Лица, оценившие свое здоровья на «хорошо» или «отлично», среди пенсионеров до 62 лет составляют 30,2\%, 62 лет и старше - всего 3,9\%. Худшие оценки превалировали среди лиц 62-х лет и старше.

Анализ самооценки военными пенсионерами стоматологического здоровья показал, что оценки стоматологического здоровья достоверно ниже оценок здоровья в целом (табл. 3).

Таблича 3.

Распределение военных пенсионеров по самооценке стоматологического и общего здоровья, \%

\begin{tabular}{|c|c|c|c|c|c|c|c|}
\hline & $\begin{array}{c}\text { От- } \\
\text { лично }\end{array}$ & Хорошо & Удовл. & $\begin{array}{c}\text { Пло- } \\
\text { хо }\end{array}$ & $\begin{array}{c}\text { Очень } \\
\text { плохо }\end{array}$ & $\begin{array}{c}\text { Не опре- } \\
\text { делился }\end{array}$ & $\begin{array}{c}\text { Средний } \\
\text { балл }\end{array}$ \\
\hline Баллы & 1 & 2 & 3 & 4 & 5 & 6 & \\
\cline { 1 - 5 } Оценка здоровья & 0,7 & 10,9 & 77,9 & 9,5 & 0,7 & 0,3 & $3,54 \pm 0,80$ \\
\hline $\begin{array}{c}\text { Оценка стома- } \\
\text { тологического } \\
\text { здоровья }\end{array}$ & 0 & 5,7 & 47,3 & 36,6 & 8,7 & 1,7 & $2,99 \pm 0,54$ \\
\hline
\end{tabular}


В приведенной паре шкальных величин корреляция составила 0,413 ( $<<0,001)$. Следовательно, оценки стоматологического здоровья достоверно ниже оценок здоровья в целом, что подтверждается и расчетом среднего балла (чем ниже балл, тем лучше оценка). Средняя оценка стоматологического здоровья составила $3,53 \pm 0,8$ баллов (от 1 балла - отлично до 5 бал-

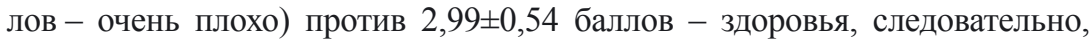
стоматологическое здоровье достоверно хуже здоровья в целом (рис. 1).

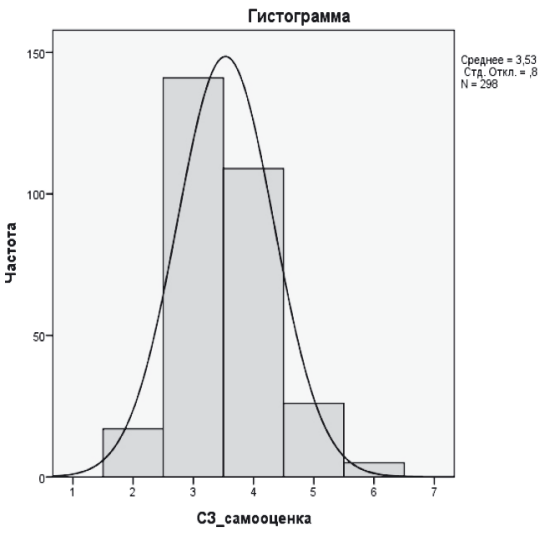

A

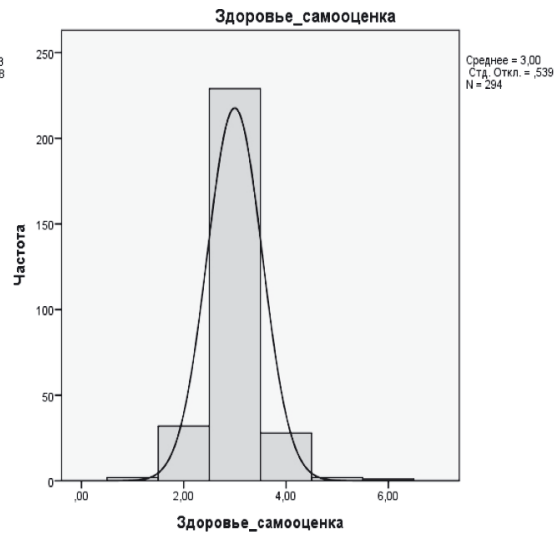

Б

Рис. 1. Самооценка военными пенсионерами стоматологического здоровья (С3) и здоровья в целом Обозначения: баллы оценки здоровья: 1 - отлично, 2 - хорошо, 3 - удовлетворительно, 4 - плохо, 5 - очень плохо.

Среди причин обращения к стоматологу среди военных пенсионеров абсолютно превалирует необходимость протезирования в связи с частичной утратой зубов $(76 \%)$, затем замена 2-х и более коронок $(8 \%)$ и пломбирование зубов (5\%) (рис. 2).

При этом установлено, что пенсионеры 61 года и старше чаще обращаются к стоматологу по причинам протезирования (на 13,9\%), в связи с утратой зубов (на $3,4 \%$ ), с заменой 2 -х и более коронок (на $2,9 \%$ ). В остальных случаях чаще обращаются пенсионеры до 61 года: с связи с необходимостью пломбирования (на 8,5\%), кариеса зубов (на 6,6\%), проблемами десен и пародонтита (на 2,4\%) и консультацией (на 2,4\%).

Среди военных пенсионеров большинство $(64,8 \%)$ проявляют пассивный интерес к информации о сохранении здоровья зубов, т.е. если ин- 
формация «попадает на глаза», что говорит об актуальности расширения санитарного просвещения военнослужащих, но в более ранние периоды во время учебы и военной службы. Только 10,4\% активно ищут информацию по данному вопросу. При этом четверть $(24,8 \%)$ либо не интересуются этим вопросом $(17,4 \%)$, либо воспринимают такую информацию как рекламу, которой «не доверяют».

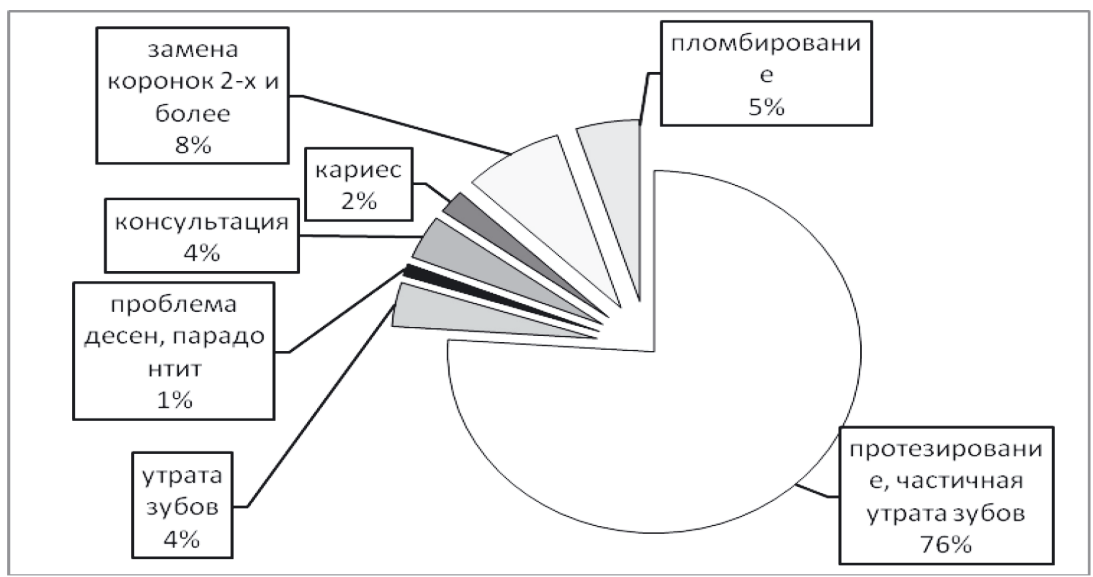

Рис. 2. Распределение военных пенсионеров по причинам обращения к стоматологу

Причины стоматологических заболеваний военные пенсионеры видят в следующих факторах: на первом месте отмечается влияние внешней среды (46,7\%), на втором - нервно-эмоциональное перенапряжение и стрессы (39,0\%), на третьем - неудовлетворительное питание $(28,3 \%)$. Далее идут такие причины, как условия труда $(27,7 \%)$, нездоровый образ жизни $(20,7 \%)$, наследственность $(19,0 \%)$, неудовлетворительная стоматологическая помощь (18,3\%).

Проведенной анализ связи информированности и интереса к новым методам поддержания стоматологического здоровья с причинами стоматологических заболеваний среди военных пенсионеров позволил выявить следующее. Уровень знаний о методах сохранения здоровья зубов и сохранения стоматологического здоровья связан с двумя основными факторами. Во-первых, это неудовлетворительная стоматологическая помощь, которую респонденты связывают с недостаточной информированностью по данному вопросу («знают самое необходимое» $11,1 \%$ против $28,8 \%$ 
остальных $(\mathrm{p}<0,05)$ и «знают кое-что» 79,9\% против 59,3\% остальных $(\mathrm{p}<0,05))$. Во-вторых, это нездоровый образ жизни, который респонденты связывают с недостаточной информированностью по данному вопросу («знают самое необходимое» $20 \%$ против $31,2 \%$ остальных $(\mathrm{p}<0,05)$ и «знают кое-что» 70\% против 56,5\% остальных $(\mathrm{p}<0,05)$, «не знают ничего» $10,0 \%$ против $4,3 \%$ остальных $(\mathrm{p}<0,05))$.

При этом наибольший интерес к новым методам профилактики стоматологических заболеваний проявляют те респонденты, которые признают вредные условия труда и нерациональное питание факторами, ответственными за нарушение стоматологического здоровья. Действительно, именно в группе, признающих вредные условия труда, наибольшее число лиц, проявляющих активный интерес к новым методам профилактики стоматологических заболеваний $(20,5 \%$ против $6,5 \%$ остальных $(\mathrm{p}<0,05))$. А в группе, признающих нерациональное питание, наибольшее число лиц, проявляющих активный интерес к новым методам профилактики стоматологических заболеваний $(14,3 \%$ против $3,3 \%$ остальных $(\mathrm{p}<0,05))$ и пассивный интерес $(66,7 \%$ против $65,1 \%(\mathrm{p}<0,05))$.

Выполнение рекомендаций стоматолога имеет место у $24,1 \%$ респондентов и в их семьях. Более половины респондентов и их семей выполняют рекомендации не всегда и не все в семье $(63,4 \%), 12,4 \%$ - когда необходимо.

Большинство военных пенсионеров указали, что предпочитают государственную стоматологическую помощь, то есть обслуживаются только в ведомственных лечебно-профилактических учреждениях (70,3\%, сред-

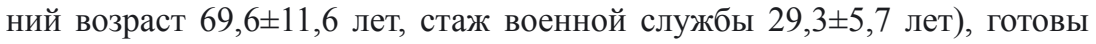
частично оплачивать стоматолога только 7,8\% опрошенных (средний возраст $61,8 \pm 11,6$ лет, стаж военной службы 27,6 6 , 1 лет), 1,0\% (средний

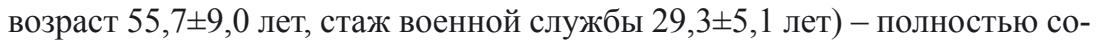

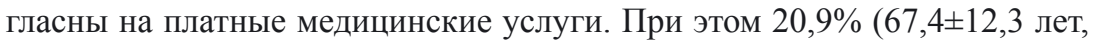
стаж военной службы 28,2 6,4 лет) вообще не задумывались над этим вопросом.

Оценка ортопедической стоматологической помощи военными пенсионерами в основном дается как «удовлетворительная» - 77,0\%, оценку «хорошо» поставили 11,3\%, «плохо» и «очень плохо»- 3,4\%. Оставшиеся респонденты не смогли оценить уровень ортопедической помощи.

Наиболее часто информацию о методах протезирования военные пенсионеры получают в ходе консультации у стоматолога $(81,0 \%)$, но при этом около 50,0\% указали на средства массовой информации, включая рекламу, 21,3\% - друзей и знакомых, 18,0\% - членов семьи. 
Объективные причины визита военных пенсионеров к врачу стоматологу-ортопеду представлены в табл. 4. Как видно из табл. 4, дефект зубного ряда (мост) включенный, дефект коронковой части зуба, дефект зубного ряда концевой (съемный протез) и расцементировка коронки составляют 95\% от всех причин визита к врачу стоматологу-ортопеду, причем дефект зубного ряда (мост) включенный, дефект коронковой части зуба - более $70 \%$.

Таблица 4.

Причины визита к врачу стоматологу-ортопеду

\begin{tabular}{|l|c|c|c|}
\hline \multicolumn{1}{|l|}{ Причина визита к врачу } & Частота & Проценты & Накопленный процент \\
\hline $\begin{array}{l}\text { Дефект зубного ряда } \\
\text { (мост) включенный }\end{array}$ & 127 & 42,3 & 42,3 \\
\hline $\begin{array}{l}\text { Дефект коронковой части } \\
\text { зуба }\end{array}$ & 87 & 29,0 & 71,3 \\
\hline $\begin{array}{l}\text { Дефект зубного ряда кон- } \\
\text { цевой (съемный протез) }\end{array}$ & 64 & 21,3 & 92,6 \\
\hline Расцементировка коронки & 13 & 4,3 & 96,9 \\
\hline Другое & 4 & 1,3 & 98,2 \\
\hline $\begin{array}{l}\text { Коррекция съемного про- } \\
\text { теза }\end{array}$ & 3 & 1,0 & 99,2 \\
\hline Снятие коронки & 2 & 0,7 & 100,0 \\
\hline Всего & 300 & 100,0 & 100,0 \\
\hline
\end{tabular}

В большинстве случаев врачу стоматологу-ортопеду удается оказать необходимую стоматологическую помощь данному контингенту, однако в 7,2\% отмечается отсутствие результата, что чаще всего связано с отсутствием данных пациентов на повторном приеме.

Например, снятие коронки, устранение дефекта коронки и коррекция съемного протеза устраняется в 100\% случаев; дефект зубного ряда концевой (съемный протез) устраняется в 96,8\% случаев и $3,2 \%$ - результата нет; дефект коронковой части устраняется в $94,0 \%$ случаев и в $6 \%$ - нет; дефект зубного ряда (мост включенный) устраняется в $86,9 \%$ случаев, в 1,6\% случаев результат достигнут на $50 \%$ и в 11,5\% случаев результат не достигнут; расцементировка коронки устраняется в $84,6 \%$ случаев, в 7,7\% случаев результат достигается на $50 \%$ и в $7,7 \%$ случаев - на $25 \%$ ( $=0,007)$.

Результативность стоматологической ортопедической помощи не связана с величиной КПУ, наличием гингивита, парадонтита или повышенной стираемостью зубов пациента. 


\section{Заключение}

Таким образом, результаты проведенного исследования позволили получить медико-социальную характеристику военных пенсионеров и их отношения к организации стоматологической помощи и профилактике стоматологических заболеваний.

Уровень медицинской грамотности можно оценить как низкий, о чем свидетельствуют невыполнение рекомендаций стоматолога совсем или не в полной мере (суммарно свыше $80 \%$ респондентов), отсутствие пациентов на повторном приеме у врача-стоматолога при прохождении лечения.

Отмечается низкий уровень информированности военных пенсионеров по вопросам профилактики и лечения стоматологических заболеваний.

Данное исследование подтверждает необходимость разработки комплекса мероприятий по стоматологической реабилитации военных пенсионеров.

\section{Список литературы}

1. Beard J.R., Biggs S., Bloom D.E., Fried L.P., Hogan P., Kalache A., et al. Introduction. In: Beard J.R., Biggs S., Bloom D.E., Fried L.P., Hogan P., Kalache A., et al., editors. Global population ageing: peril or promise? Geneva: World Economic Forum; 2012:4-13. (http://www3.weforum.org/ docs/WEF_GAC_Global PopulationAgeing_Report_2012.pdf, accessed 24 July 2015).

2. Чуйкин С.В., Штанько М.И. Влияние возрастных изменений критериев стоматологического здоровья на качество жизни пациентов пожилого и старческого возраста // Институт стоматологии. 2013. №2 (59). С. 18.

3. Русинова О.В., Тарасова Н.В., Алямовский В.В. Психологические аспекты стоматологического приема у лиц пожилого и старческого возраста // В мире научных открытий. 2013. № 11.4. С. 307-315.

4. Christensen K., Doblhammer G., Rau R., Vaupel J.W. Ageing populations: the challenges ahead. Lancet. 2009 Oct 3;374(9696):1196-208. doi: http://dx.doi. org/10.1016/S0140-6736(09)61460-4 PMID: 19801098

5. Численность населения Российской Федерации по возрасту на 1 января 2017 года. Режим доступа: http://www.gks.ru/wps/wcm/connect/rosstat_main/ rosstat/ru/statistics/population/ demography/\# (дата обращения 10.01.2017).

6. Жданкина А.О., Фомина А.В. Совершенствование организации лучевой диагностики лицам предпенсионного и пенсионного возраста в условиях оказания амбулаторно-поликлинической помощи // Вестник новых медицинских технологий. 2016. Т. 23. № 3. С. 243-252. 
7. Алешковский И.А., Ионцев В.А. Демографический фактор в развитии России в условиях глобализации // International Journal for Demographic and other social studies. 2012. T. 9. C.7-26.

8. Муравьева В.Н., Хорева О.О., Савченко В.В. Оценка нуждаемости в стоматологической помощи лиц пожилого и старческого возраста, находящихся в стационарных учреждениях системы социального обслуживания Ставропольского края // Социальные аспекты здоровья населения. 2015. T. 44. № 4. Режим доступа: http://vestnik.mednet.ru/content/view/704/30/ lang,ru/ (дата обращения 10.01.2017).

9. Kiyak H.A., Reichmuth M. Barriers to and enablers of older adults use of dental services // J. Dent. Educ. 2005. Vol. 69, pp. 975-986.

10. Petersen P.E., Kandelman D., Arpin S., Ogawa H. Global oral health of older people-call for public health action. Community Dent Health. 2010 Dec; 27(4) Suppl 2:257-67. PMID:21313969.

11. Алимский А.В., Вусатый В.С., Прикулс В.Ф. Медико-социальные и организационные аспекты современной геронтостоматологии // Российский стоматологический журнал. 2004. № 2. С. 34-38.

12. Характеристика стоматологической заболеваемости офицеров запаса и в отставке по данным эпидемиологического обследования / Г.И. Прохватилов, А.М. Шелепов, В.Ф. Черныш, Г.А. Гребнев, В.А. Николаев // Пародонтология. 2007. №2 (43). С. 54-58.

13. Гринин В.М., Авдеев Д.А. Характеристика гигиенического состояния тканей пародонта у летчиков летно-подъемного состава военной авиации // Стоматология для всех. 2012. № 3. С. 24-25.

14. Свинцов А.А. Государственные гарантии прав граждан пожилого возраста и инвалидов на охрану здоровья // Профилактическая и клиническая медицина. 2014. №4 (53). С. 49-53.

15. Гаджиев Р.С., Рагимова Р.Ш. Качество медицинской помощи населению пожилого и старческого возраста в городских поликлиниках // Проблемы социальной гигиены, здравоохранения и истории медицины. 2011. № 2. С. 36-39.

16. Кузнецов С.В. Анализ контроля качества и доступности медицинской помощи в рамках комплексной стоматологической реабилитации пациентов пожилого и старческого возраста // Вестник Росздравнадзора. 2014. № 2. C. $22-26$.

17. Гринин В.М., Авдеев Д.А. Особенности оказания стоматологической помощи летчикам военной авиации в условиях специализированного ЛПУ // Российский стоматологический журнал. 2012. № 3. С. 52-53. 
18. Солдатов И.К., Савченко И.Ф., Лемешкин Р.Н. Обращаемость за стоматологической помощью в поликлиническом звене центрального военного округа // Вестник Национального медико-хирургического центра им. Н.И. Пирогова. 2014. Т. 9. № 4. С. 84-88.

19. Медико-статистический анализ стоматологической заболеваемости и амбулаторно-стоматологической помощи в войсковом звене / Шелепов А.М., Гребнев Г.А., Солдатов И.К., Петров С.В., Игнатов М.Ю. // Вестник Российской военно-медицинской академии. 2014. № 4 (48). С. 208-214.

20. Стоматологическое здоровье нации и пути его сохранения (вклад военных стоматологов в профилактику и лечение заболеваний зубов, пародонта и слизистой оболочки по полости рта) / Иорданишвили А.К., Лобейко В.В., Самсонов В.В., Черныш В.Ф., Солдатова Л.Н. // Пародонтология. 2015. T. 20. № 1 (74). C. 78-80.

\section{References}

1. Beard J.R., Biggs S., Bloom D.E., Fried L.P., Hogan P., Kalache A., et al. Introduction. In: Beard J.R., Biggs S., Bloom D.E., Fried L.P., Hogan P., Kalache A., et al., editors. Global population ageing: peril or promise? Geneva: World Economic Forum; 2012:4-13. http://www3.weforum.org/docs/WEF_GAC_Global PopulationAgeing_Report_2012. pdf (accessed 24 July 2015).

2. Chuykin S.V., Shtan'ko M.I. Vliyanie vozrastnykh izmeneniy kriteriev stomatologicheskogo zdorov'ya na kachestvo zhizni patsientov pozhilogo i starcheskogo vozrasta. [Influence of age changes of dental health criteria on quality of life of elderly and old patients]. Institut stomatologii [Institute of dentistry]. 2013. №2 (59). P. 18.

3. Rusinova O.V., Tarasova N.V., Alyamovskij V.V. Psihologicheskie aspekty stomatologicheskogo priema u lic pozhilogo i starcheskogo vozrasta [Psychological aspects of dental treatment of geriatric patients]. V mire nauchnyh otkrytij [In the World of Scientific Discoveries]. 2013. № 11.4, pp. 307-315.

4. Christensen K., Doblhammer G., Rau R., Vaupel J.W. Ageing populations: the challenges ahead. Lancet. 2009 Oct 3;374(9696):1196-208. doi: http://dx.doi. org/10.1016/S0140-6736(09)61460-4 PMID: 19801098.

5. The population of the Russian Federation at the age on 1 January 2017. Available at: http://www.gks.ru/wps/wcm/connect/rosstat_main/rosstat/ru/ statistics/population/ demography/\# (accessed January 10, 2017).

6. Zhdankina A.O., Fomina A.V. Sovershenstvovanie organizacii luchevoj diagnostiki licam predpensionnogo i pensionnogo vozrasta $\mathrm{v}$ uslovijah okazanija ambulatorno-poliklinicheskoj pomoshhi [Improvement of radiology diagnostics organization for people of pre-retirement and retirement age in the provi- 
sion of outpatient care]. Vestnik novyh medicinskih tehnologij [Journal of New Medical Technologies]. 2016. Vol. 23. № 3, pp. 243-252.

7. Aleshkovskiy I.A., Iontsev V.A. Demograficheskiy factor v razvitii Rossii v usloviyakh globalizatsii [The demographic factor in the development of Russia in the conditions of globalization]. International Journal for Demographic and other social studies. 2012. Vol. 9, pp. 7-26.

8. Muravyeva V.N., Khoreva O.O., Savchenko V.V. Ocenka nuzhdaemosti v stomatologicheskoj pomoshhi lic pozhilogo i starcheskogo vozrasta, nahodjashhihsja $\mathrm{v}$ stacionarnyh uchrezhdenijah sistemy social'nogo obsluzhivanija Stavropol'skogo kraja [Needs assessment in dental care among the elderly in residential social service institutions of Stavropol territory]. Social'nye aspekty zdorov'ja naselenija [Social aspects of public health]. 2015. Vol. 44. № 4. Available at: http://vestnik. mednet.ru/content/view/704/30/lang,ru/ (accessed January 10, 2017).

9. Kiyak H.A., Reichmuth M. Barriers to and enablers of older adults use of dental services. J. Dent. Educ. 2005;69: 975-986.

10. Petersen P.E., Kandelman D., Arpin S., Ogawa H. Global oral health of older people-call for public health action. Community Dent Health. 2010 Dec; 27(4) Suppl 2:257-67. PMID:21313969.

11. Alimsky A.V., Vusaty V.S., Prikuls V.F. Mediko-social'nye i organizacionnye aspekty sovremennoj gerontostomatologii [Medical, social and managerial aspects of modern gerontostomatology]. Rossijskij stomatologicheskij zhurnal [Russian stomatological journal]. 2004. № 2. pp. 34-38.

12. Harakteristika stomatologicheskoj zabolevaemosti oficerov zapasa i v otstavke po dannym jepidemiologicheskogo obsledovanija [Characteristics of dental morbidity of the reserve military officers and retired by the epidemiological screening data] / G.I. Prohvatilov, A.M. Shelepov, V.F. Chernysh, G.A. Grebnev, V.A. Nikolaev. Parodontologija [Periodontology]. 2007. №2 (43), pp. 54-58.

13. Grinin V.M., Avdeev D.A. Harakteristika gigienicheskogo sostojanija tkanej parodonta u letchikov letno-pod\#emnogo sostava voennoj aviacii [The characteristic of hygienic condition of the periodontal tissues of military aircraft's pilots]. Stomatologija dlja vseh [Dentistry for all]. 2012. № 3, pp. 24-25.

14. Svintsov A.A. Gosudarstvennye garantii prav grazhdan pozhilogo vozrasta i invalidov na ohranu zdorovya [State guarantees the rights of the elderly and persons with disabilities to health]. Profilakticheskaja i klinicheskaja medicina [Preventive and Clinical Medicine]. 2014. №4 (53), pp.49-53.

15. Gadjiev R.S., Ragimova R. Sh. Kachestvo medicinskoj pomoshhi naseleniju pozhilogo i starcheskogo vozrasta $\mathrm{v}$ gorodskih poliklinikah [The quality of medical care to the patients of elderly and old age in municipal polyclinics]. 
Problemy socialnoj gigieny, zdravoohranenija i istorii mediciny [Problems of social hygiene, public health and history of medicin]. 2011. № 2, pp. 36-39.

16. Kuznetsov S.V. Analiz kontrolja kachestva i dostupnosti medicinskoj pomoshhi v ramkah kompleksnoj stomatologicheskoj reabilitacii pacientov pozhilogo i starcheskogo vozrasta [Evaluation of quality control and availability of medical care in comprehensive dental rehabilitatio of elderly patients]. Vestnik Roszdravnadzora [Bulletin of Roszdravnadzor]. 2014. № 2, pp. 22-26.

17. Grinin V.M., Avdeev D.A. Osobennosti okazanija stomatologicheskoj pomoshhi letchikam voennoj aviacii v uslovijah specializirovannogo LPU [Peculiarities of provision of the medical aid to military pilots under conditions of a specialized therapeutic and prophylactic facility]. Rossijskij stomatologicheskij zhurnal [Russian Journal of Dentistry]. 2012. № 3, pp. 52-53.

18. Soldatov I.K., Savchenko I.F., Lemeshkin R.N. Obrashhaemost za stomatologicheskoj pomoshhju v poliklinicheskom zvene centralnogo voennogo okruga [Negotiability for dental care of accepted contingent in policlinics ling of central military district]. Vestnik Nacionalnogo mediko-hirurgicheskogo centra im. N.I. Pirogova [Bulletin of Pirogov National Medical \& Surgical Center]. 2014. Vol. 9. № 4, pp. 84-88.

19. Mediko-statisticheskij analiz stomatologicheskoj zabolevaemosti i ambulatorno-stomatologicheskoj pomoshhi v vojskovom zvene [Medical and statistical analysis of dental diseases and outpatient dental care in military link] / Shelepov A.M., Grebnev G.A., Soldatov I.K., Petrov S.V., Ignatov M.Y. Vestnik Rossijskoj voenno-medicinskoj akademii [Bulletin of the Russian Military Medical Academy]. 2014. № 4 (48), pp. 208-214.

20. Stomatologicheskoe zdorovie nacii i puti ego sohranenija (vklad voennyh stomatologov v profilaktiku i lechenie zabolevanij zubov, parodonta i slizistoj obolochki po polosti rta) [Dental health of the nation and its way of saving (the contribution of the military dentists in the prevention and treatment of diseases of the teeth, periodontal and mucosal oral)] / Iordanishvili A.K., Lobejko V.V., Samsonov V.V., Chernysh V.F., Soldatova L.N. Parodontologija [Periodontology]. 2015. Vol. 20. № 1 (74), pp. 78-80.

\section{ДАННЫЕ ОБ АВТОРАХ}

Фомина Анна Владимировна, доктор фармацевтических наук, профессор, зав. кафедрой общественного здоровья, здравоохранения и гигиены Федеральное государственное автономное образовательное учреждение высшего образования «Российский университет дружбын народов» 
ул. Миклухо-Маклая, 6, г. Москва, 117198, Российская Федеращия fomina_av@pfur.ru

Тарараева Татьяна Юрьевна, аспирант кафедры общественного здоровья, здравоохранения и гигиены

Федеральное государственное автономное образовательное учреждение высшего образования «Российский университет дружбы народов»

ул. Миклухо-Маклая, 6, г. Москва, 117198, Российская Федерачия ttatju-19@mail.ru

\section{DATA ABOUT AUTHORS}

Fomina Anna Vladimirovna, Doctor of Pharmaceutical Sciences, Professor, Head of the Department of Public Health and Hygiene RUDN University 6, Mikluho-Maklaya Str., Moscow, 117198, Russian Federation fomina_av@pfur.ru SPIN-code: $5385-2586$ ORCID: 0000-0002-2366-311x Researcher ID: B-4950-2017 Scopus Author ID: 7006304378

Tararaeva Tatjana Jurevna, Postgraduate of the Department of Public Health and Hygiene RUDN University 6, Mikluho-Maklaya Str., Moscow, 117198, Russian Federation ttatju-19@mail.ru 